\title{
Social behavior change programming for public health emergencies: Lessons learned from the USAID Zika response in Latin America and the Caribbean
}

Breakthrough RESEARCH

Follow this and additional works at: https://knowledgecommons.popcouncil.org/departments_sbsr-pgy How does access to this work benefit you? Let us know!

\section{Recommended Citation}

Breakthrough RESEARCH. 2019. "Social behavior change programming for public health emergencies: Lessons learned from the USAID Zika response in Latin America and the Caribbean," Programmatic Research Brief. Washington, DC: Population Council. 


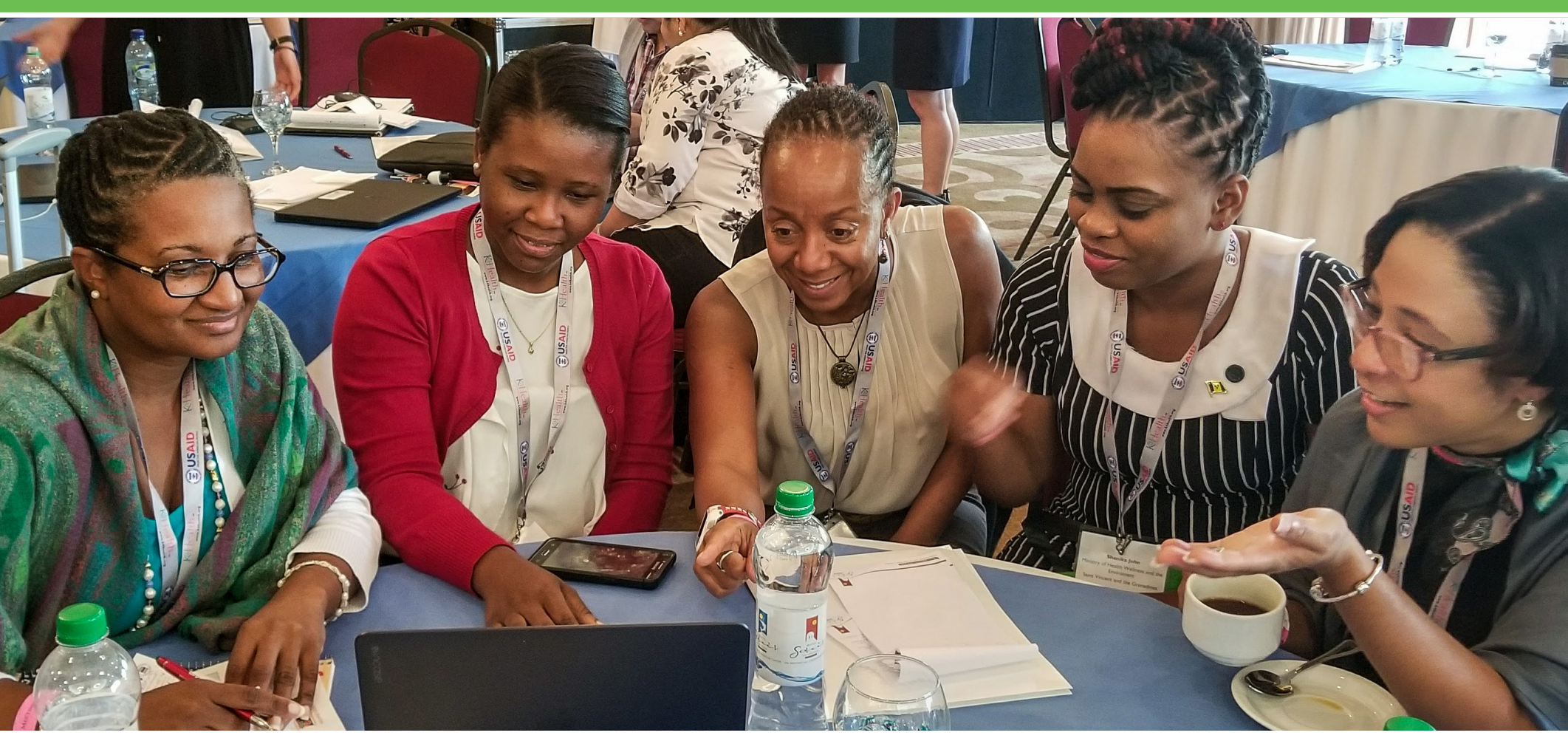

\section{Social Behavior Change Programming for Public Health Emergencies}

\section{LESSONS LEARNED FROM THE USAID ZIKA RESPONSE IN LATIN AMERICA AND THE CARIBBEAN}

After the World Health Organization (WHO) declared a public health emergency in 2016, the U.S. Department of State dedicated funding for the United States Agency for International Development (USAID) Zika response in Latin America and the Caribbean to ensure healthy pregnancies and births in affected countries (see Box 1).

USAID and its implementing partners (IPs) collaborated closely with national health ministries and local stakeholders to respond to the crisis. USAID pursued a multipronged approach concentrating on four lines of effort, with gender integration and community engagement as crosscutting themes: 1) social and behavior change (SBC) communication (see Box 2); 2) vector (or mosquito) control; 3) service delivery; 4) research and innovation.

This brief provides insights from the SBC line of effort during USAID's Zika response. Its purpose is to share lessons learned during the response to inform future SBC programming for public health emergencies. 


\section{How Can Lessons From the USAID Zika Response's SBC Programming Inform Future Health Emergency Responses?}

As Zika case numbers subsided over time and the USAID Zika response ended, USAID and its partners sought to understand the strengths, weaknesses, gaps, and challenges experienced through the SBC technical area to inform future programming for public health emergency responses. Between August 2018 and November 2019, the Breakthrough RESEARCH project reviewed program documentation, conducted in-depth stakeholder interviews, implemented an online survey, and assessed data collection instruments used by IPs during the response. The following seven recommendations summarize the lessons learned from this effort. More detailed information is available in Breakthrough RESEARCH's "Lessons Learned for SBC Programming From the USAID Zika Response" report. ${ }^{6}$

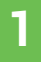

Coordinate with SBC stakeholders at multiple levels early and often.

Stakeholder coordination and collaboration throughout the Zika response has been recognized by partners as an "unprecedented" success and should be replicated in future public health emergencies. In response to the initial challenges of organizing a cohesive response among numerous partners spread across multiple countries, SBC technical working groups were established in Washington D.C., within each country, and at community levels to support coordination of activities and promote collaborative SBC efforts. Where possible, USAID tried to use existing
BOX 1

\section{WHAT IS ZIKA AND WHY IS IT A} PUBLIC HEALTH CONCERN?

- The Zika virus is a communicable disease primarily spread by Aedes aegypti mosquitoes, which also transmit other arboviruses including dengue, yellow fever, and chikungunya.

- Zika can be transmitted through sexual intercourse and from pregnant mothers to unborn children. ${ }^{2}$ It is known to cause neurological problems, such as congenital Zika syndrome, when acquired during pregnancy. ${ }^{3}$

- Many people infected with Zika do not develop symptoms, which may lead to a lower perceived risk of infection and subsequently limit preventive behavior. ${ }^{4}$

- Aedes aegypti mosquitoes are most commonly present in urban environments and can breed indoors, even in small bodies of water such as flowerpots. ${ }^{5}$
BOX 2

\section{WHAT IS SOCIAL AND BEHAVIOR CHANGE?}

Social and behavioral change (SBC) programming includes activities or interventions that aim to change health-seeking behaviors by raising awareness, reducing misinformation, promoting social norms that enable these behaviors, and addressing the barriers that prevent individuals, families, and communities from practicing behaviors that improve health outcomes. ${ }^{7}$

Examples of SBC activities in the USAID Zika response include approaches that were targeted to:

- Increase the uptake of Zika prevention behaviors.

- Increase the demand for and use of commodities and services for prevention and treatment among target populations (e.g., mosquito repellents).

- Shift attitudes by addressing social norms (e.g., condom use during pregnancy).

- Reduce the barriers to consistent practice of prevention behaviors (e.g., building skills to effectively remove vector breeding sites). 
structures for country-level coordination, such as technical working groups organized by the ministries of health. This multi-tiered approach helped promote synergy at all levels of the response:

REGIONAL LEVEL: An SBC working group based in Washington, D.C., allowed headquarters staff from IPs to gain a better understanding of the work and scope of other partners, leading to enhanced coordination at the country level.

COUNTRY LEVEL: IPs used existing cross-sectoral working groups (mesas técnicas) to update each other on activities, find opportunities for synergy, avoid duplication, share SBC best practices, and learn from one another.

COMMUNITY LEVEL: Coordination of community dialogues, care groups, and mobilization campaigns ensured community members' participation and ownership, as well as coordination with local government.

\section{Determine priority preventive behaviors through a participatory process with all stakeholders at the beginning of the response.}

The urgency of the USAID Zika response in the early stages of implementation-coupled with gaps in scientific knowledge about the virus - led to promotion of more than 30 variations of preventive behaviors and related messages in the first year. Of these promoted behaviors, not all were supported by evidence regarding their effectiveness in preventing arboviruses. Given this, USAID recognized the need to develop and implement a collaborative, evidence-based process for prioritizing behaviors that would be most effective for prevention. The prioritization process used the best available evidence and considered contextual factors that may impede behavior change. It resulted in two technical documents: the first outlining seven prioritized behaviors and the second providing detailed technical specifications to guide IPs in using more focused and effective SBC messages. ${ }^{8} \mathrm{~A}$ peer-reviewed manuscript documented how the process drew from available evidence. ${ }^{9}$

\section{Integrate SBC programming into other technical areas.}

The Zika response showed that SBC efforts have the potential to be more effective when incorporated into other technical areas as a cross-cutting approach. One of the Zika response's
BOX 3

WHAT IS HUMAN-CENTERED

DESIGN?

Human-centered design (HCD) works through

a formative process that consists of jointly

generating ideas for addressing behavioral

barriers and programmatic gaps, and iteratively

working with target populations to design, test,

and refine jointly determined solutions, interven-

tions, and programmatic approaches. ${ }^{10}$

most significant successes was the organic collaboration that developed between vector-control IPS and SBC IPS to integrate elements of SBC into vector control activities, particularly in strengthening their interpersonal communication (IPC) approaches during home visits. Analysis of data from Breakthrough RESEARCH studies indicate that when IPC is layered onto action directly related to vector control during a household visit, such as applying larvicide to a water storage container, it leads to higher levels of self-reported prevention behaviors. ${ }^{11}$ Additionally, SBC partners benefited from vector-control IPs' entomological expertise during the behavioral prioritization process.

\section{Engage community members to develop context-appropriate solutions through participatory design methods.}

The Zika response highlighted the need to leverage community knowledge and ownership to better understand and plan for the most effective solutions in each context. Early and more extensive applications of human-centered design (HCD) or other highly participatory design methods might have contributed toward reducing cultural barriers to adopting preventive behaviors (see Box 3). For example, in Jamaica, IPs successfully piloted an HCD process to develop several solutions to reduce mosquito breeding sites in household water storage tanks. ${ }^{12}$ Community input in developing and iterating upon new designs promotes a sense of collective ownership of the solutions developed. This buy-in can potentially influence community members' likelihood of adopting preventive behaviors. In the context of condensed emergency response timelines, $\mathrm{HCD}$ or other participatory processes are advantageous because they can be adapted to fit the shorter timeframe required in emergencies. 


\section{Identify and mobilize SBC expertise at all levels to ensure availability of skills to implement effective SBC programming.}

At the onset of the response, IPs with strong SBC technical expertise at headquarters put considerable efforts toward recruiting staff with the most appropriate SBC experience, as well as strengthening SBC capacity among both local teams and community volunteers. The USAID-supported Breakthrough ACTION project was tasked with providing SBC technical assistance to the ministries of health and, later, IPs of the Zika response. Breakthrough ACTION identified training needs and opportunities across IPs, developed materials, and led capacity-strengthening activities in several countries. UNICEF-a partner in the USAID Zika response- also developed a diploma course to strengthen local professionals' SBC capacity. Across the response, the following three strategies enabled partners to enhance SBC skills among local staff:

- A new IPC training curriculum was developed for frontline workers during home visits.

A needs assessment identified enhanced IPC as an area that could improve frontline workers' engagement with community members and help communities prevent Zika transmission. Breakthrough ACTION developed an IPC training curriculum on how to share technical information, while also developing rapport with households during visits. Nearly 1,000 frontline community volunteers, health promoters, vector-control workers, trainers, and program coordinators involved in the USAID Zika response were trained using the new curriculum.

\section{- Workshops were conducted for IPs to strengthen} SBC activities.

Breakthrough ACTION held workshops to help IPs use available behavioral data for programmatic decisionmaking and midcourse program adjustments, among other things. Other workshops introduced country government counterparts to an innovative, systematic process that combines the principles of communication, behavioral economics, community engagement, and HCD. ${ }^{13}$ These workshops had a cascade effect; following trainings, IPs were able to provide SBC technical assistance within their own projects, resulting in a more nuanced understanding of SBC programming at local levels.

\section{- A new diploma program for risk communication.}

UNICEF institutionalized SBC capacity strengthening in the region by partnering with local universities in Guatemala and Honduras to develop a diploma program for risk communication based on their Communication for Development methodology. UNICEF considered the development of this diploma program a great success that continues to contribute to increasing expertise for SBC locally.

These capacity-strengthening efforts-coupled with stakeholders' involvement in the Zika response-led IPs and ministries of health to report an increase in their capacity to develop and implement effective SBC activities. The development of skills to more effectively deliver SBC work in the region has positioned partners to better respond to future public health emergencies.

\section{Prioritize formative research from the beginning of a response.}

Due to the sense of urgency at the outset of the Zika response, SBC activities began immediately once projects established local presence. While such prompt action helped address the ongoing epidemic as soon as possible, it meant that some steps, such as developing and implementing formative research, were not prioritized. Formative research allows program implementers to understand the health problem being addressed and uncover the determinants of the behaviors that the program is trying to change in order to design appropriate strategies. In the case of the Zika response, IPs perceived that conducting formative research might have informed early program development, testing of prevention messages and materials, and development of SBC activities to maximize behavioral impact. For example, formative research might have helped SBC and community engagement partners identify sociocultural and gender norms to develop solutions that were more likely to address community concerns, fears, or mistrust. However, once formative research was undertaken in Year 2, and with the gradual adoption of the prioritized Zika prevention behaviors, the Zika response saw improved SBC program design, including appropriate channels and accompanying materials for target audiences.

\section{Coordinate monitoring, evaluation, research, and learning (MERL) activities.}

Throughout the Zika response, survey questions used to monitor and evaluate activities were inconsistent across settings. This lack of consistency prevented comparative monitoring across the response that could have contributed to improved Zika prevention strategies across settings. Given the time and resource constraints of public health 
emergency responses, creating a consistent MERL framework for SBC at the outset can help set priority objectives, harmonize measurement, align data collection, and develop research utilization plans for primary and secondary audiences. This approach should include a core set of SBC indicators and definitions that are collected in a standardized way across the response to allow for comparability across partners and countries, while also maintaining enough flexibility to include the data needs of different stakeholders and contextual factors.

Further, although many research studies were conducted throughout the response, leading to a data-rich environment, Zika stakeholders perceived no clear mechanism with which to share data among partners to learn from the broader response in a timely way and avoid duplicative research. With increased IP-led coordination, results of formative research, monitoring data, and other focused studies could be more easily shared among partners in the same geographic area. A dedicated research and evaluation partner could also facilitate a coordinated and participatory process for developing an agreed-upon MERL framework and maximize learning from a data-rich environment.

\section{SBC Programming for Future Public Health Emergencies}

The timing of the next major public health emergency is unknown, but it is certain to occur. For Zika alone, a recent WHO report identified 61 countries at risk for outbreaks due to the presence of the Aedes aegypti mosquito in highly populated places. ${ }^{14} \mathrm{SBC}$ strategies should be an integral part of any public health emergency response and, when implemented effectively, can make a profound impact on efforts to ensure people in affected countries are protected against disease. Future public health emergency responses should incorporate the seven core lessons from USAID and partners' experiences with the recent Zika epidemic to increase high-quality SBC programming that safeguards the health and well-being of people around the world.

\section{Key Recommendations}

\section{Strategic Design and Implementation of SBC Programming}

1. Coordinate with SBC stakeholders at all levels early and often.

2. Determine priority preventive behaviors through a participatory process with all stakeholders at the beginning of the response.

3. Integrate SBC into other technical areas.

4. Engage community members to develop contextappropriate solutions through participatory design methods.

5. Identify and mobilize SBC expertise at all levels to ensure availability of skills to implement effective SBC programming.

\section{Monitoring, Evaluation, Research, and Learning}

6. Prioritize formative research from the beginning of a response.

7. Coordinate monitoring, evaluation, research, and learning activities. 


\section{References}

1 World Health Organization (WHO). 2016. Zika Strategic Response Plan. Geneva, Switzerland: WHO.

2 WHO. 2016. Zika Strategic Response Plan.

3 Haby, Michelle et al. 2018. "Prevalence of asymptomatic Zika virus infection: a systematic review," Bulletin of the World Health Organization 96: 402-413D; Centers for Disease Control and Prevention (CDC). 2018. "Congenital Zika Syndrome \& Other Birth Defects." Available from www.cdc.gov/pregnancy/zika/testing-follow-up/zika-syndrome-birth-defects.html.

4 Haby, Michelle et al. 2018. "Prevalence of asymptomatic Zika virus infection: a systematic review."

5 CDC. How to Prevent the Spread of the Mosquito that Causes Dengue. Available from https://www.cdc.gov/dengue/resources/vectorcontrolsheetdengue.pdf.

6 Silva, Martha et al. 2019. Lessons Learned for SBC Programming From the USAID Zika Response. Washington, DC: Population Council.

7 WHO. 2018. Zika Virus. Geneva: Switzerland, WHO. Available from https://www.who.int/en/news-room/fact-sheets/detail/zika-virus; Doran, Frances and Nancarrow, Susan. 2015. "Barriers and facilitators of access to first-trimester abortion services for women in the developed world: a systematic review," Journal of Family Planning and Reproductive Health Care 41: 170-180.

8 Breakthrough ACTION + RESEARCH. 2018. Technical Specifications Content Guide for Behaviors With High Potential to Prevent Zika. Baltimore, MD: Zika Communication Network. Available from https://www. zikacommunicationnetwork.org/index.php/resources/technical-specifications-content-guide-behaviors-high-potential-prevent-zika.

9 Murray, SA et al. 1994. "Listening to local voices: Adapting rapid appraisal to assess health and social needs in general practice," British Medical Journal 308(6930): 698-700.

10 IDEO.org. "What is human-centered design?" Available from https:// www.designkit.org/human-centered-design.

11 Silva, Martha et al. 2019. Lessons Learned for SBC Programming From the USAID Zika Response.

12 Breakthrough ACTION. 2019. Reinventing Water Storage in Jamaica: A Human-Centered Design Approach to Zika Prevention. Washington, DC: Population Council.

13 Breakthrough ACTION. 2019. Reinventing Water Storage in Jamaica: A Human-Centered Design Approach to Zika Prevention. Washington, DC: Population Council.

14 WHO. 2019. Zika Epidemiology Update. Geneva, Switzerland: WHO. Available from https://www.who.int/emergencies/diseases/zika/zika-epidemiology-update-july-2019.pdf?ua=1.

\section{Acknowledgements}

This programmatic research brief describes work led by Tulane University and Population Council under Breakthrough RESEARCH. The brief was produced by Population Reference Bureau. The Breakthrough RESEARH project would like to acknowledge and thank USAID and Breakthrough ACTION for their significant contributions to this body of work. We would also like to acknowledge input from implementing partners in the USAID Zika response, ministries of health, and USAID Missions in the region.

For more information on the lessons learned for SBC Programming from the USAID Zika response, see the full report.

\section{Suggested citation:}

Breakthrough RESEARCH. 2019. "Social Behavior Change Programming for Public Health Emergencies: Lessons Learned From the USAID Zika Response in Latin America and the Caribbean," Programmatic Research Brief. Washington, DC: Population Council.

\section{Photo credit:}

Zika implementing partners participate in a share fair to discuss community engagement in the USAID Zika response. (c) 2018, K4Health

\section{(?) The Population Council. All rights reserved.}

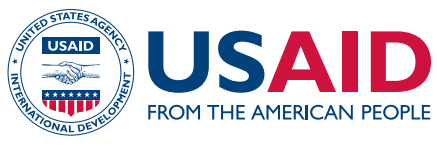

Breakthrough RESEARCH is made possible by the generous support of the American people through the United States Agency for International Development (USAID) under the terms of cooperative agreement no. AID-OAA-A-17-00018. The contents of this document are the sole responsibility of the Breakthrough RESEARCH and Population Council and do not necessarily reflect the views of USAID or the United States Government.

\section{安}

Tulane University

POPULATION COUNCIL

Ideas. Evidence. Impact.

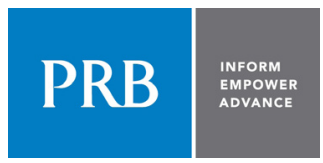

\section{Breakthrough RESEARCH FOR SOCIAL \& BEHAVIOR CHANGE

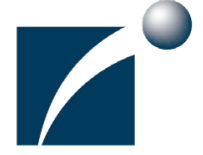

Breakthrough RESEARCH catalyzes social and behavior change (SBC) by conducting state-ofthe-art research and evaluation and promoting evidence-based solutions to improve health and development programs around the world. Breakthrough RESEARCH is a consortium led by the Population Council in partnership with Avenir Health, ideas42, Institute for Reproductive Health at Georgetown University, Population Reference Bureau, and Tulane University. 